\title{
研究通讯
}

\section{关于丢番图方程 $x^{3} \pm 1=D y^{2}$}

对于丢番图方程

$x^{3} \pm 1=D y^{2}, x^{3} \pm 1=3 D y^{2}, D>2, D$ 无平方因 子且不能被 3 或 $6 k+1$ 形的素数整除, 设上式中四 个方程的正整数解 $(x, y)$ 的总个数为 $T$, Ljunggren (Skr. Norske Vid. Ak ad. Oslo. I. 9 (1942), 53) 证明了 $T \leqslant 1$ ，他的证明方法不是初等的.
本文用初等的方法完全解决了上面四个方程, 证明了 $T=0$, 即证明了

定理 形如上面的四个丢番图方程, 除开平 凡解 $x= \pm 1, y=0$ 以外,均无其他的整数解.

柯召 孙琦

(四川大学数学系)

\section{$(M+1)$ 级有界变差函数 $M=3,4,5,6,7,8,10$}

定义 1 设 $f(x)$ 是定义在闭区间 $[a, b]$ 上的 有限实函数，

$$
\Delta_{h}^{m} f(x)=\sum_{r=0}^{m}(-1)^{r} C_{m}^{r} f[x+(m-r) h],
$$

$\Delta$ 表示 $[a, b]$ 的任一分法:

$$
\Delta: a=x_{0}<x_{1}<\cdots \cdots<x_{n}=b \quad(n \geqslant 2),
$$
作和:

$$
\begin{aligned}
& S_{\Delta}^{m+1}(f)=\sum_{i=1}^{x-1} \mid \frac{\Delta_{x_{i+1}-x_{i}}^{m} f\left(x_{i}\right)}{\left(\frac{x_{i+1}-x_{i}}{m}\right)^{m}} \\
& -\frac{\frac{m}{\Delta_{x_{i}-x_{i-1}}} f\left(x_{i-1}\right)}{m}
\end{aligned}
$$

对于所有可能的分法 $\Delta$,

$$
\operatorname{Sup}_{\Delta}\left\{S_{\Delta}^{m+1}(f)\right\}=\bigvee_{a}^{b+1}(t)
$$

称为 $f(x)$ 在区间 $[a, b]$ 上的 $(m+1)$ 级全变差, 若 $\bigvee_{a}^{b+1}(f)<+\infty$, 则称 $f(x)$ 是在区间 $[a, b]$ 上的 $(m+1)$ 级有界变差函数. 以 $V^{m+1}[a, b]$ 表示在 $[a, b]$ 上定义的所有的有界变差函数的集合.

定义 2 设 $f(x)$ 是定义在闭区间 $[a, b]$ 上的 有限实函数, 若对 $[a, b]$ 上的任意三点 $x_{1}, x_{2}, x_{3}$, $a \leqslant x_{1}<x_{2}<x_{3} \leqslant b$, 使不等式:

$$
\frac{\Delta_{x_{2}-x_{1}}^{m} f\left(x_{1}\right)}{\left(\frac{x_{2}-x_{1}}{m}\right)^{m}} \leqslant \frac{\frac{\Delta_{x_{3}-x_{2}}^{m}}{m} f\left(x_{2}\right)}{\left(\frac{x_{3}-x_{2}}{m}\right)^{m}}
$$

第 6 期
恒成立, 则称 $f(x)$ 为 $[a, b]$ 上定义的 $m$ 级凸函数.

定理 1 若函数 $f(x) \in \mathrm{V}^{m+1}[a, b](m=3,4$, $5,6,7,8,10)$, 则 $f(x)$ 在 $[a, b]$ 上连续.

定理 2 函数 $f(x) \in \mathrm{V}^{m+1}[a, b](m=3,4$, $5,6,7,8,10)$ 的充分必要条件是 $f(x)$ 可以表示为 一个 $m$ 级有界变差函数的不定积分:

$$
f(x)=\int_{a}^{x} g(t) d t+f(a),
$$

其中 $g(x) \in \mathrm{V}^{m}[a, b]$.

定理 3 函数 $f(x) \in V^{m+1}[a, b](m=3,4$, $5,6,7,8,10)$ 的充分必要条件是 $f(x)$ 可以表示为 一个有界变差函数的 $m$ 重不定积分:

$$
\begin{aligned}
f(x)= & \int_{a}^{x} d t_{n-1} \int_{a}^{s_{m-1}} \cdots \cdots \int_{a}^{t_{1}} g(t) d t \\
& +\sum_{k=0}^{m-1} a_{k} x^{k},
\end{aligned}
$$

其中 $g(x)$ 为 $[a, b]$ 上的有界变差函数, 而 $a_{0}, a_{1}$, $\ldots . . . a_{m-1}$ 为一些常数.

定理 4 函数 $f(x) \in V^{m+1}[a, b](m=3,4$, $5,6,7,8,10)$ 的充分必要条件是 $f(x)$ 可以表示为 二个 $m$ 级凸函数之差:

$$
f(x)=f_{1}(x)-f_{2}(x),
$$

其中 $f_{i}(x)(i=1,2)$ 为 $m$ 级凸函数, 此二函数在端 点 $[a, b]$ 的 $m$ 阶广义导数:

$$
\begin{gathered}
f_{i+}^{(m)}(a)=\lim _{k \rightarrow 0+} \Delta_{k}^{m} f_{i}(a) / h^{m}, \\
f_{i-}^{(m)}(b)=\lim _{k \rightarrow 0+} \Delta_{-k}^{m} f_{i}(b) / h^{m} \quad(i=1,2)
\end{gathered}
$$

存在且有限.

王冠闽 (福建南靖山城中学) 